\title{
Incorporation of Hydroxyapatite into Glass Ionomer Cement (GIC) Formulated Based on Alumino-Silicate-Fluoride Glass Ceramics from Waste Materials
}

\author{
Wan Nurshamimi Wan Jusoh ${ }^{1}$, Khamirul Amin Matori ${ }^{1,2, *}$, Mohd Hafiz Mohd Zaid ${ }^{1}$, Norhazlin Zainuddin ${ }^{3}$ \\ Mohammad Zulhasif Ahmad Khiri ${ }^{2}$, Nadia Asyikin Abdul Rahman ${ }^{1}$, Rohaniah Abdul Jalil ${ }^{1}$ and Esra Kul ${ }^{4}$ D \\ 1 Department of Physics, Faculty of Science, Universiti Putra Malaysia, UPM Serdang, Selangor 43400, \\ Malaysia; mimieywanjusoh@gmail.com (W.N.W.J.); mhmzaid@upm.edu.my (M.H.M.Z.); \\ nadiaxrahman84@gmail.com (N.A.A.R.); niajalil20@gmail.com (R.A.J.) \\ 2 Material Synthesis and Characterization Laboratory, Institute of Advanced Technology, \\ Universiti Putra Malaysia, UPM Serdang, Selangor 43400, Malaysia; mzulhasif@gmail.com \\ 3 Department of Chemistry, Faculty of Science, Universiti Putra Malaysia, UPM Serdang, \\ Selangor 43400, Malaysia; norhazlin@upm.edu.my \\ 4 Department of Prosthodontics, Faculty of Dentistry, Ataturk University, 25030 Erzurum, Turkey; \\ esra.kul@atauni.edu.tr \\ * Correspondence: khamirul@upm.edu.my; Tel.: +60-16-267-3321
}

check for updates

Citation: Wan Jusoh, W.N.; Matori, K.A.; Mohd Zaid, M.H.; Zainuddin, N.; Ahmad Khiri, M.Z.; Abdul

Rahman, N.A.; Abdul Jalil, R.; Kul, E. Incorporation of Hydroxyapatite into Glass Ionomer Cement (GIC) Formulated Based on Alumino-Silicate-Fluoride Glass Ceramics from Waste Materials. Materials 2021, 14, 954. https:// doi.org/10.3390/ma14040954

Received: 17 October 2020

Accepted: 20 November 2020

Published: 18 February 2021

Publisher's Note: MDPI stays neutral with regard to jurisdictional claims in published maps and institutional affiliations.

Copyright: (C) 2021 by the authors. Licensee MDPI, Basel, Switzerland. This article is an open access article distributed under the terms and conditions of the Creative Commons Attribution (CC BY) license (https:// creativecommons.org/licenses/by/ $4.0 /)$.
Abstract: Glass ionomer cement (GIC) is a well-known restorative material applied in dentistry. The present work aims to study the effect of hydroxyapatite (HA) addition into GIC based on physical, mechanical and structural properties. The utilization of waste materials namely clam shell (CS) and soda lime silica (SLS) glass as replacements for the respective $\mathrm{CaO}$ and $\mathrm{SiO}_{2}$ sources in the fabrication of alumino-silicate-fluoride (ASF) glass ceramics powder. GIC was formulated based on ASF glass ceramics, polyacrylic acid (PAA) and deionized water, while $1 \mathrm{wt}$.\% of HA powder was added to enhance the properties of the cement samples. The cement samples were subjected to four different ageing times before being analyzed. In this study, the addition of HA caused an increment in density and compressive strength results along with ageing time. Besides, X-ray Diffraction (XRD) revealed the formation of fluorohydroxyapatite (FHA) phase in HA-added GIC samples and it was confirmed by Fourier Transform Infrared (FTIR) analysis which detected OH-F vibration mode. In addition, needle-like and agglomeration of spherical shapes owned by apatite crystals were observed from Field Emission Scanning Electron Microscopy (FESEM). Based on Energy Dispersive $X$-ray (EDX) analysis, the detection of chemical elements in the cement samples were originated from chemical compounds used in the preparation of glass ceramics powder and also the polyacid utilized in initiating the reaction of GIC.

Keywords: ASF glass ceramics; clam shell; glass ionomer cement; hydroxyapatite; soda lime silica glass

\section{Introduction}

A form of dental restoration and luting material, called glass ionomer cement (GIC), is widely used in dental application. In the early of 70's, Alan Wilson and Brian Kent introduced GIC as water-based cement derived from silicate-based glass and polycarboxylate salt [1]. This water-based substance forms essentially when there is a reaction between aqueous polyacrylic acid solution and fluoro-aluminosilicate glass powder [1-3].

GIC has desirable properties which encourage their clinical uses in dentistry such as it provides a direct bonding to tooth structure [4-6], exhibit a good biocompatibility and has the ability to release fluoride which is important as anticariogenic agent in preventing the occurrence of tooth decay [7]. Furthermore, the higher stability of GIC when involved in aqueous environment and also the results of low toxicity when applied to tooth are the 
advantages of GIC in dental application. Despite having good properties, there is some limitation that limits GIC from extensive use in dentistry as filling and restorative material. GIC has been shown to have weak mechanical and physical properties including low fracture strength and hardness, reduced wear resistance and opaqueness [8]. Besides, GIC is very brittle and this proved the low physical strength of GIC to be used as dental material.

Therefore, there are many efforts that have been focused on the modification of GIC so that the physical and mechanical properties of GIC can be enhanced. One of the ways is by incorporating hydroxyapatite into the GIC composition. Hydroxyapatite (HA) is an inorganic compound with a constitution equivalent to natural bone mineral and is well known as an apatite group (a group of mineral phosphate). HA is represented by the chemical formula of $\mathrm{Ca}_{10}\left(\mathrm{PO}_{4}\right)_{6}(\mathrm{OH})_{2}$, differ with other apatite compounds by containing hydroxyl end-member of the apatite group [4,5]. HA present as a major component of mineral in bone and teeth with calcium-to-phosphate ratio of $1.67(\mathrm{Ca} / \mathrm{P}=1.67)$ and hexagonal crystal structure $[4,5,8]$. According to Ramsden and co-workers, HA has osteoconductive and bioactive properties which make it favorable in orthopedics and dental application [9].

Alumino-silicate-fluoride (ASF) glass ceramics composition used in the formulation of GIC is believed to have good properties and favorable for dental materials [10-12]. The design of ASF glass ceramics composition is based on the $45 \mathrm{~S} 5$ bioactive glass system used by Larry L. Hench which implicated a combination of glass network formers, modifiers and intermediates oxides [13,14]. The use of waste materials like clam shell (CS) and soda lime silica (SLS) glass as replacement of silicate and calcite sources, respectively in the synthesis of glass ceramics can save the production cost and reduce the environmental issues regarding the disposal problems. According to previous literatures, the general composition of SLS glass consists of $70-75 \mathrm{wt} . \%$ of $\mathrm{SiO}_{2}, 12-16 \mathrm{wt} . \%$ of $\mathrm{Na}_{2} \mathrm{O}$ and $10-15 \mathrm{wt} . \%$ of $\mathrm{CaO}[15,16]$, meanwhile CS contains more than $98 \% \mathrm{CaC}$ which encouraged it uses as biomaterial [17].

The key purpose of this work is to investigate the influence of HA addition on the composition of glass ceramics in GIC formulation based on physical, mechanical and structural properties. Although some work on the addition of HA into GIC has been performed, a deeper study can be gained especially involving the participation of ASF glass ceramics as the base silicate powder in the formulation of GIC. ASF glass ceramics composition with the existence of fluorapatite (FA) had been studied by several researchers [10-12] and the involvement of FA crystal phase in the GIC formulation is crucial since it can give effect to the properties of the resulting cement. Moreover, the utilization of waste materials which are CS and SLS glass in the fabrication of ASF glass ceramics and subsequently formulated into GIC can attract a great interest to researchers since there is limited studies on the use of waste materials in the GIC formulation. However, the GIC formulated based on ASF glass ceramics as base silicate powder was observed to produce inadequate mechanical strength which restricted their uses as dental material. Thus, the study on the addition of HA into the GIC formulation can help in improving the properties of resulting GIC. Besides, the effect of ageing time of the cement samples was also investigated in this study.

\section{Materials and Experimental Procedure}

\subsection{Materials}

Raw materials used as sources of $\mathrm{CaO}$ and $\mathrm{SiO}_{2}$ were derived from CS and SLS glass, respectively. Anadara granosa sp. CS were collected from the beachside of Pantai Cahaya Bulan, Kelantan, Malaysia, while SLS glass which was 'Jalen' soy sauce brand obtained from restaurants near to Universiti Putra Malaysia, Selangor, Malaysia.

The glass ceramics component of the cement involved the mixing of raw materials and chemical components such as $\mathrm{CaF}_{2}$ (R\&M Chemicals, Semenyih, Selangor, Malaysia; 99.95\%), $\mathrm{P}_{2} \mathrm{O}_{5}$ (Alfa Aesar, a Johnson Matthey Company, Lancashire, UK; 99.99\%) and $\mathrm{Al}_{2} \mathrm{O}_{3}$ (Alfa Aesar, a Johnson Matthey Company, UK; 99.5\%). Meanwhile, HA powder used was reagent grade powder (Sigma Aldrich, a Merck KGaA Company, Darmstadt, Germany; $\geq 90 \%$ ) with CAS No. $1306-06-5$ and molecular weight $\left(\mathrm{M}_{\mathrm{W}}\right) \sim 502.31$. The participation 
of dried powder of polyacrylic acid (PAA) with $\mathrm{M}_{\mathrm{W}} \sim 30,000$ obtained from Advance Healthcare Ltd., Willenhall, UK and deionized water as a medium of reaction was crucial in the cement formation.

\subsection{Preparation of CS and SLS Glass Powder}

Preparation of raw materials was started by the cleaning process of collected CS and SLS glass in order to remove dirt from the materials. For CS, calcium oxide $(\mathrm{CaO})$ was obtained from the calcination process of $\mathrm{CS}$ at $900{ }^{\circ} \mathrm{C}$ for $3 \mathrm{~h}$ as explained in several studies [10-12]. In this process, carbon dioxide $\left(\mathrm{CO}_{2}\right)$ in the form of gas was removed from aragonite and calcite $\left(\mathrm{CaCO}_{3}\right)$ which were the majority components of the CS. After that, both CS and SLS glass went through the same process, whereby they were crushed, plunged and sieved before getting $\leq 45 \mu \mathrm{m}$ sized CS and SLS glass powder.

\subsection{Synthesis of ASF Glass Ceramics Composition}

ASF composition was fabricated by mixing 25 wt.\% SLS, 20 wt.\% CS, 20 wt. \% $\mathrm{P}_{2} \mathrm{O}_{5}$, 20 wt. $\% \mathrm{Al}_{2} \mathrm{O}_{3}$ and 15 wt. $\% \mathrm{CaF}_{2}$ with $30 \mathrm{~g}$ of the total weight composition. After the five components were mixed homogeneously in alumina crucible, they were subjected to a melting process at $1500{ }^{\circ} \mathrm{C}$ in the furnace for $4 \mathrm{~h}$. Next, the quenching process was done by pouring the molten glass into water, thus producing frits. Subsequently, the obtained frits were manually crushed by using plunger and grinded by using mortar and pestle, which then formed $\leq 45 \mu \mathrm{m}$-sized powder of ASF glass ceramics.

\subsection{Formulation of Control and Modified GIC Samples}

GIC was formulated by ASF glass ceramics, PAA and deionized water with ratio of 3:1:1 (glass ceramics:PAA:water). The setting reaction of cement required the combining of the three components on the glass plate for approximately $60 \mathrm{~s}$. Right after $60 \mathrm{~s}$, the cement was filled and pressed into stainless-steel mold $(6 \mathrm{~mm} \times 4 \mathrm{~mm})$ to produce cylindrical shaped pellets and then dried at $37^{\circ} \mathrm{C}$ for an hour. Next, the cement went through ageing process for 1, 7, 14 and 21 days in deionized water before characterized. In this study, a total of 30 pellets of GIC and 30 pellets of GIC1 samples were formed. GIC sample represented the GIC without HA addition while GIC1 sample represented GIC with the addition of 1 wt.\% of HA powder into GIC. The GIC1 samples were prepared by mixing ASF glass ceramics with HA powder before formulated into GIC in the proportion of 3 based on the ratio as stated previously.

\subsection{Characterization of Control and Modified GIC Samples}

The cement samples were characterized by density measurement, compressive strength test, X-ray Diffraction (XRD), Fourier Transform Infrared (FTIR), Field Emission Scanning Electron Microscopy (FESEM) and Energy Dispersive X-ray (EDX).

\subsubsection{Density}

The density $(\varrho)$ was evaluated based on Archimedes' principle at room temperature [18]. The total of 24 samples in pellet form were weighed before being immersed into distilled water with a density of $1.0 \mathrm{~g} / \mathrm{cm}^{3}$ and the test were repeated for three times. After that, the weights of each pellet were taken and resulting density with unit gram per centimeter cubic $\left(\mathrm{g} / \mathrm{cm}^{3}\right)$ were calculated based on formula:

$$
\rho_{\text {sample }}=\frac{\mathrm{W}_{\text {air }}}{\mathrm{W}_{\text {air }}-\mathrm{W}_{\text {distilled water }}} \times \rho_{\text {distilled water }}
$$

where $W_{\text {air }}=$ weight in air, $W_{\text {distilled water }}=$ weight in distilled water and $\rho_{\text {distilled water }}=$ density of distilled water $=1.0 \mathrm{~g} / \mathrm{cm}^{3}$. 


\subsubsection{Compressive Strength Test}

Compressive strength of the samples was determined by using Universal Testing Machine (UTM) from Instron (Instron, Norwood, MA, USA) with a model of 5566. The load frame applied was up to $10 \mathrm{kN}$ with crosshead of $1 \mathrm{~mm} / \mathrm{min}$ and the tests were repeated up to three times to avoid error. The total of 24 samples were prepared in bulk form with cylindrical shape of $6 \mathrm{~mm}$ diameter and $10 \mathrm{~mm}$ height $(6 \mathrm{~mm} \times 4 \mathrm{~mm})$. The compressive strength $(\sigma)$ of the sample was calculated by referring to the formula:

$$
\sigma=4 \mathrm{~F} / \pi \mathrm{d}^{2}
$$

where, $\mathrm{F}=$ maximum load applied in $\mathrm{kN}$, and $\mathrm{d}=$ the average diameter of sample in $\mathrm{mm}$. The results of compressive strength were presented in MPa unit with two decimal places.

\subsubsection{X-ray Diffraction (XRD)}

Samples in the form of powder were sent for XRD spectroscopy by using a machine of Philips (Model: PW 3040/60) with $\mathrm{Cu} \mathrm{K}_{\alpha}$ radiation equipped with $40 \mathrm{kV}$ accelerating voltage and $30 \mathrm{~mA}$ input current. The range of $2 \theta$ value was between $20^{\circ}$ to $80^{\circ}$ and the outcome was examined by using X'Pert Highscore (Malvern Panalytical, Worcestershire, UK).

\subsubsection{Fourier Transform Infrared (FTIR) Spectroscopy}

The powder samples were examined under Perkin Elmer (Model: Spectrum100 series, Perkin Elmer, Shelton, WA, USA) with wavenumber of 400 to $4000 \mathrm{~cm}^{-1}$ and resolution of $4 \mathrm{~cm}^{-1}$ for determining chemical bonding existed in the samples.

\subsubsection{Field Emission Scanning Electron Microscopy (FESEM)}

FESEM characterization was conducted to determine morphology of the samples by using a machine from NOVA (Model: NANOSEM 230, FEI Company, Hillsboro, OR, USA) FEI brand. In this characterization, the powder samples were sputter-coated with silver coating before tested by using magnification of $\times 10,000$.

\subsubsection{Energy Dispersive X-ray (EDX)}

EDX testing was used for the assessment of component composition in samples. The cement samples were prepared in powder form and characterized under FEI NOVA NanoSEM 230 (FEI Company, Hillsboro, OR, USA). The EDX results were analyzed into the weight percentage of elements with two decimal places.

\subsubsection{Statistical Analysis}

The statistical analysis used for calculation of mean and standard deviation (SD) of density and compressive strength of cement samples was one-way ANOVA model from Excel 2016. The significance level was set at 0.05 . Further statistical analysis by using Tukey-Kramer post hoc test was performed to study the statistical significant difference between the samples.

\section{Results}

\subsection{Density Analysis}

Figure 1 shows the density results of GIC and GIC1 samples at different ageing time while Table 1 depicts the statistical data of the density results. According to the figure and table, the density of the GIC sample at 1 day of ageing time was $1.681 \mathrm{~g} / \mathrm{cm}^{3}$. The addition of $1 \mathrm{wt} . \%$ of HA powder into GIC formulation represented by the GIC1 sample produced density of $1.693 \mathrm{~g} / \mathrm{cm}^{3}$ at 1 day of ageing time. The density of cement samples increased with the addition of HA powder from 1.681 to $1.693 \mathrm{~g} / \mathrm{cm}^{3}$. On the other hand, the density results increased as ageing time increased. This trend can be observed in both GIC and GIC1 samples. GIC sample showed the increment in density from $1.681 \mathrm{~g} / \mathrm{cm}^{3}$ at 1 day of ageing time to $1.824 \mathrm{~g} / \mathrm{cm}^{3}$ at 21 days of ageing time. Meanwhile, GIC1 sample showed an 
increase in density value from 1 day of ageing time with $1.693 \mathrm{~g} / \mathrm{cm}^{3}$ to 21 day of ageing time with $1.839 \mathrm{~g} / \mathrm{cm}^{3}$. The highest density results were 1.824 and $1.839 \mathrm{~g} / \mathrm{cm}^{3}$ at 21 days of ageing time for GIC and GIC1 samples, respectively.

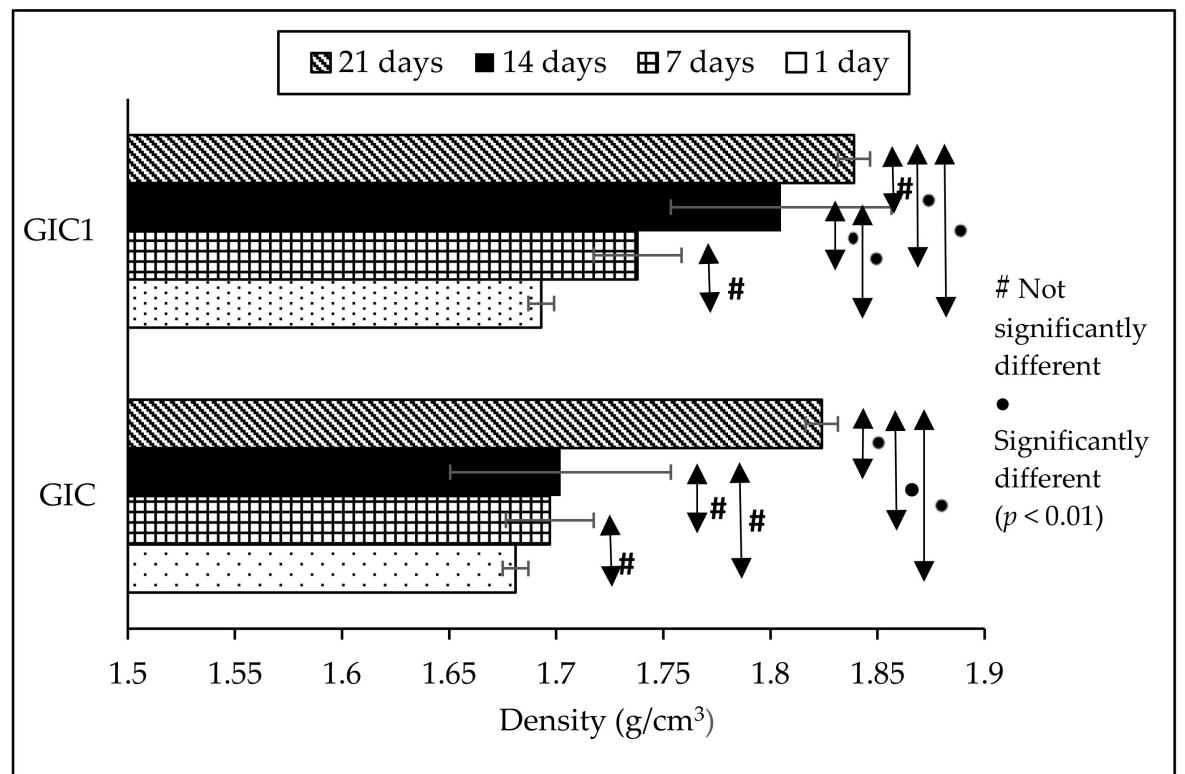

Figure 1. Density results of GIC and GIC1 samples at different ageing time (error bars indicate standard error).

Table 1. Mean density along with the standard deviation (SD) of the GIC and GIC1 samples at different ageing time.

\begin{tabular}{ccccc}
\hline \multirow{2}{*}{$\begin{array}{c}\text { Density of Sample } \\
\left(\mathbf{g} / \mathbf{c m}^{\mathbf{3}}\right)\end{array}$} & \multicolumn{4}{c}{ Ageing Time } \\
\cline { 2 - 5 } & $\mathbf{1}$ Day & 7 Days & 14 Days & 21 Days \\
\hline GIC & $1.681(0.011)^{\mathrm{a}}$ & $1.697(0.006)^{\mathrm{a}}$ & $1.702(0.015)^{\mathrm{a}}$ & $1.824(0.043)^{\mathrm{b}}$ \\
GIC1 & $1.693(0.015)^{\mathrm{a}}$ & $1.738(0.033)^{\mathrm{a}}$ & $1.805(0.007)^{\mathrm{b}}$ & $1.839(0.016)^{\mathrm{b}}$ \\
\hline
\end{tabular}

The different superscript letters (example: ${ }^{a}$ and ${ }^{b}$ ) for each sample (each row) represent significant difference between ageing time $(p<0.01)$. Meanwhile, similar superscript letters (example: ${ }^{a}$ and ${ }^{a}$ ) represent no significance difference between ageing time.

\subsection{Compressive Strength Analysis}

Figure 2 presents the compressive strength results of cement samples at different ageing time while Table 2 depicts the statistical data of the compressive strength results. The compressive strength results of GIC and GIC1 samples at 1 day of ageing time were 22.68 and $29.47 \mathrm{MPa}$, respectively. HA-added GIC was observed to result in higher compressive strength compared to GIC without HA addition, which showed increment from 22.68 to $29.47 \mathrm{MPa}$. Besides, the compressive strength results increased when ageing time increased for both samples. The compressive strength of GIC sample increased from $22.68 \mathrm{MPa}$ at 1 day of ageing time to $62.78 \mathrm{MPa}$ at 21 day of ageing time, while the compressive strength of GIC1 sample increased from $29.47 \mathrm{MPa}$ at 1 day of ageing time to $54.34 \mathrm{MPa}$ at 21 day of ageing time. The highest compressive strength results were recorded at 21 day of ageing time with 62.78 and $54.34 \mathrm{MPa}$ for the respective GIC and GIC1 samples. 


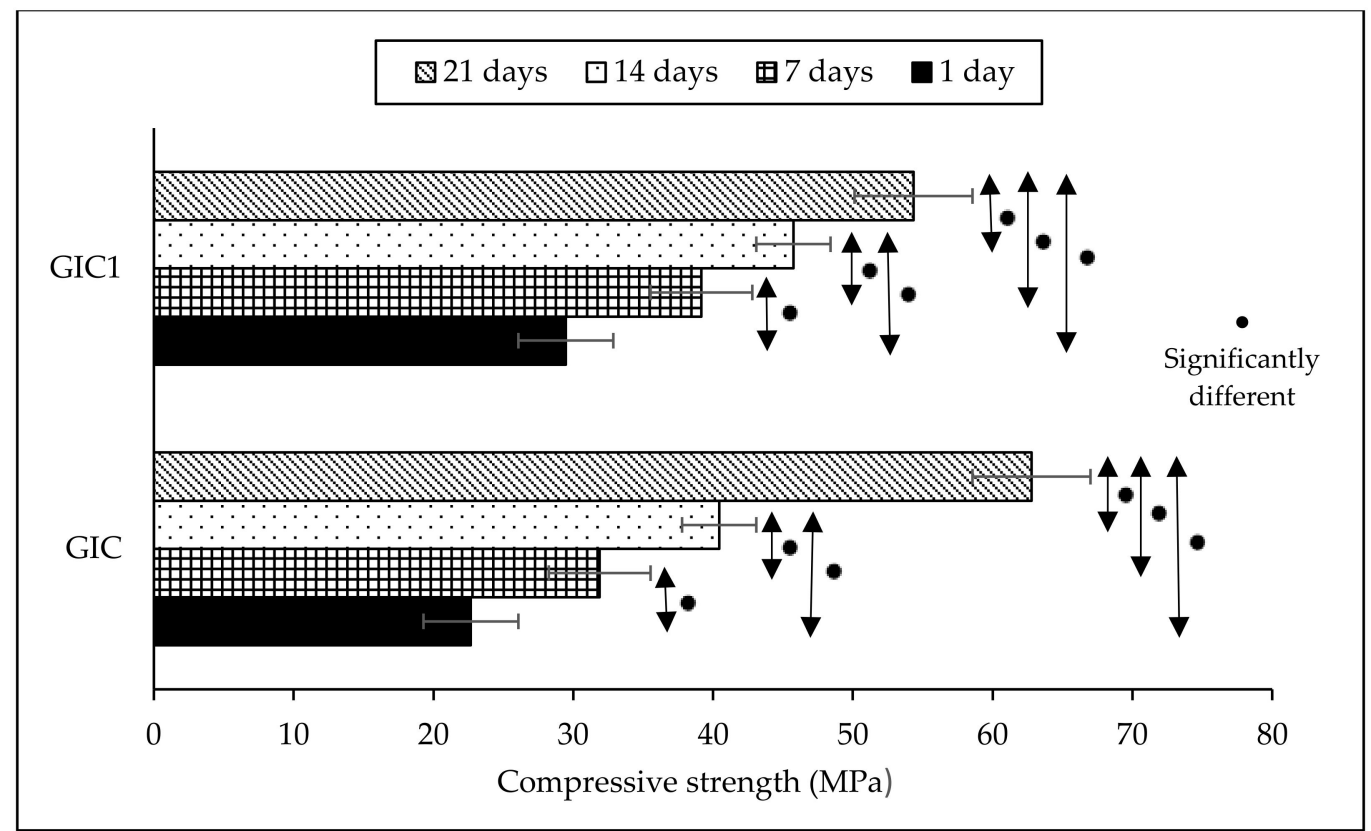

Figure 2. Compressive strength results of GIC and GIC1 samples at different ageing time (error bars indicate standard error).

Table 2. Mean compressive strength along with standard deviation (SD) of GIC and GIC1 samples at different ageing time.

\begin{tabular}{ccccc}
\hline \multirow{2}{*}{$\begin{array}{c}\text { Compressive Strength of } \\
\text { Sample (MPa) }\end{array}$} & \multicolumn{4}{c}{ Ageing Time } \\
\cline { 2 - 5 } & 1 Day & 7 Days & 14 Days & 21 Days \\
\hline GIC & $22.68(0.73)^{\mathrm{a}}$ & $31.89(0.86)^{\mathrm{b}}$ & $40.44(0.58)^{\mathrm{c}}$ & $62.78(0.21)^{\mathrm{d}}$ \\
GIC1 & $29.47(2.17)^{\mathrm{a}}$ & $39.17(1.24)^{\mathrm{b}}$ & $45.75(5.11)^{\mathrm{c}}$ & $54.34(0.63)^{\mathrm{d}}$ \\
\hline
\end{tabular}

The different superscript letters (example: ${ }^{a}$ and ${ }^{b}$ ) for each sample (each row) represent significant difference between ageing time $(p<0.01)$. Meanwhile, similar superscript letters (example: ${ }^{a}$ and ${ }^{a}$ ) represent no significance difference between ageing time.

\subsection{X-ray Diffraction (XRD) Analysis}

Figure 3 shows the XRD patterns of GIC and GIC1 samples at different ageing times. According to Figure 3, the formation of fluorapatite (FA; ICDD file No. 98-001-7206) crystal phase was observed in the GIC sample, from 1 day until 21 days of ageing time. For GIC1 sample at different ageing times, the addition of HA powder into GIC resulted in the detection of fluorohydroxyapatite (FHA; ICDD file No. 98-008-0180) crystal phase, as seen in Figure 3. Based on the observation from Figure 3, the highest crystal peak was detected at the same diffraction angle, which was $2 \theta=32^{\circ}$. No significant difference of XRD pattern was observed from 1, 7, 14 and 21 days of ageing time for both GIC and GIC1 samples.

\subsection{Fourier Transform Infrared (FTIR) Analysis}

Figure 4 shows the FTIR patterns at different ageing times for the GIC and GIC1 samples. Meanwhile, Table 3 depicts the vibrational modes assigned for FTIR spectra that existed in the cement samples. By referring to Figure 4, $\mathrm{v}_{2} \mathrm{O}-\mathrm{P}-\mathrm{O}$ bending vibrational mode was detected at $\sim 440 \mathrm{~cm}^{-1}$ while $\mathrm{v}_{4} \mathrm{O}-\mathrm{P}-\mathrm{O}$ bending mode was discovered at $\sim 570$ and $\sim 600 \mathrm{~cm}^{-1}$. Besides, the existence of the FTIR spectral band at $\sim 1020 \mathrm{~cm}^{-1}$ represented the vibrational mode of $\mathrm{v}_{3}$ asymmetric $\mathrm{P}-\mathrm{O}$ stretching. The detection of $\mathrm{C}-\mathrm{O}$ and asymmetric $\mathrm{COOH}$ vibration modes were found at wavenumbers $\sim 1460$ and $\sim 1550 \mathrm{~cm}^{-1}$, respectively. A broad and wide peak was discovered at $\sim 3400 \mathrm{~cm}^{-1}$ indicated $\mathrm{OH}$ vibration mode. The FTIR pattern of GIC1 sample at different ageing time revealed the similar vibrational 
modes existed in the sample when compared to GIC sample. However, the only difference found was the existence of $\mathrm{OH}-\mathrm{F}$ vibration mode at $~ 3550 \mathrm{~cm}^{-1}$.

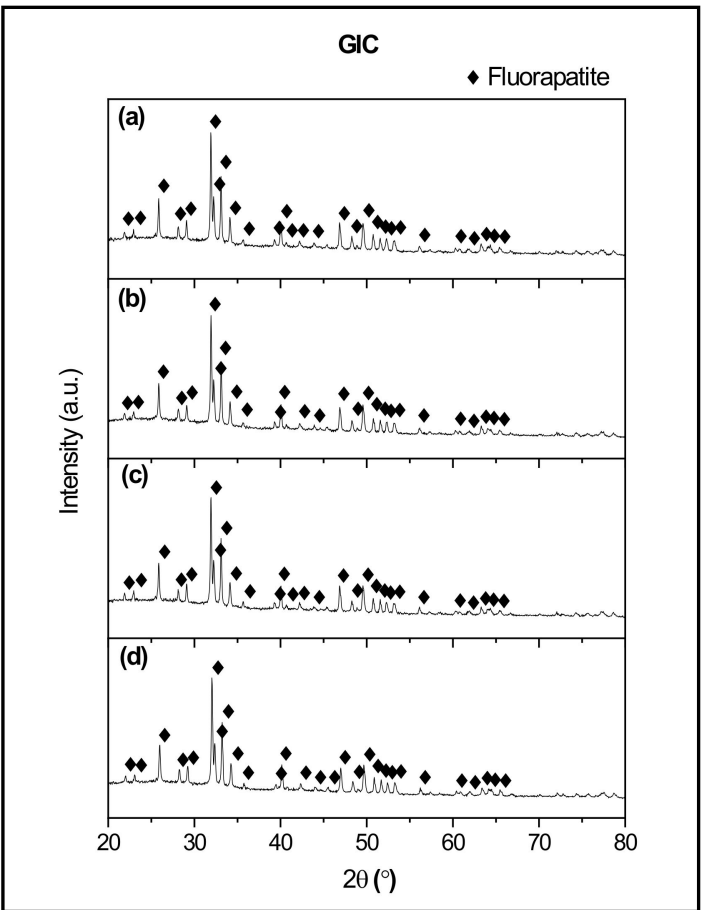

(A)

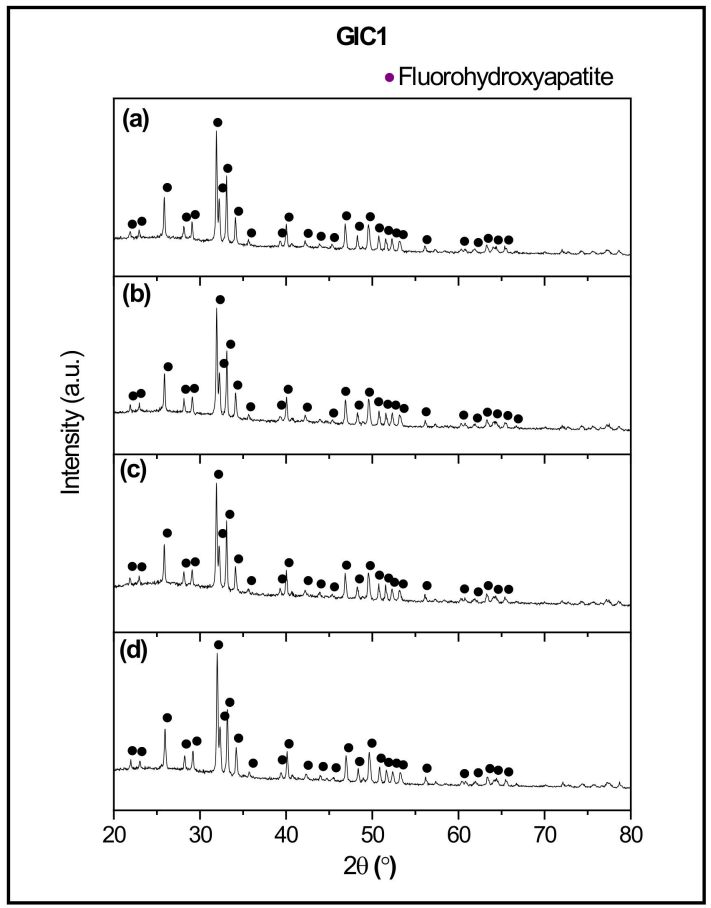

(B)

Figure 3. XRD patterns of GIC (A) and GIC1 (B) sample with (a) 1 day, (b) 7 days, (c) 14 days, and (d) 21 days of ageing time.

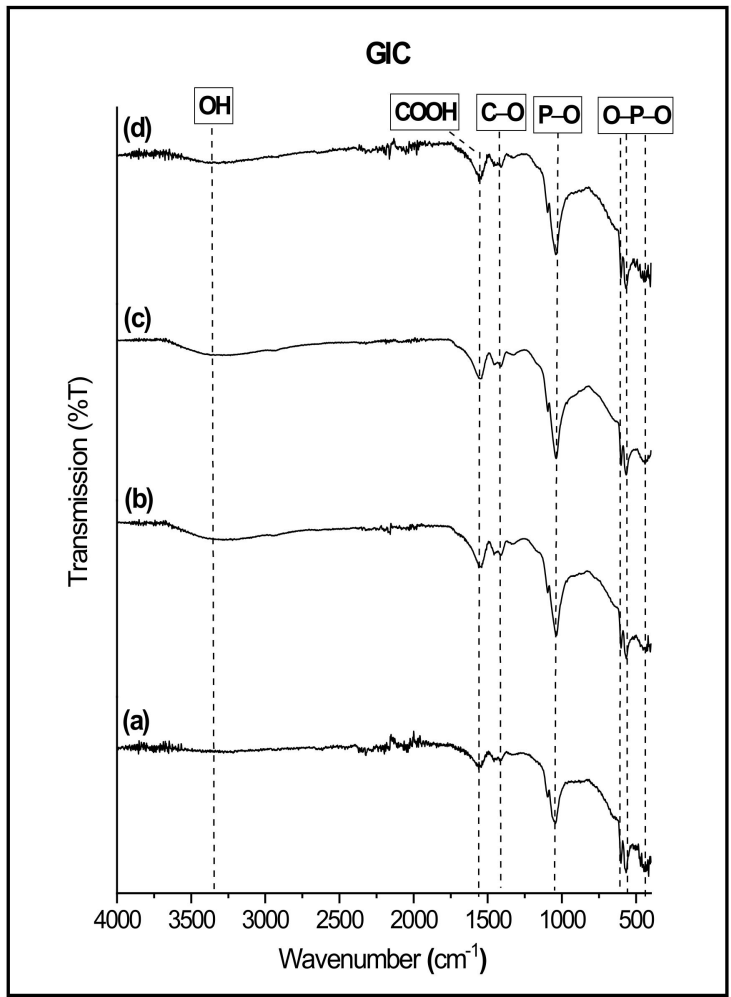

(A)

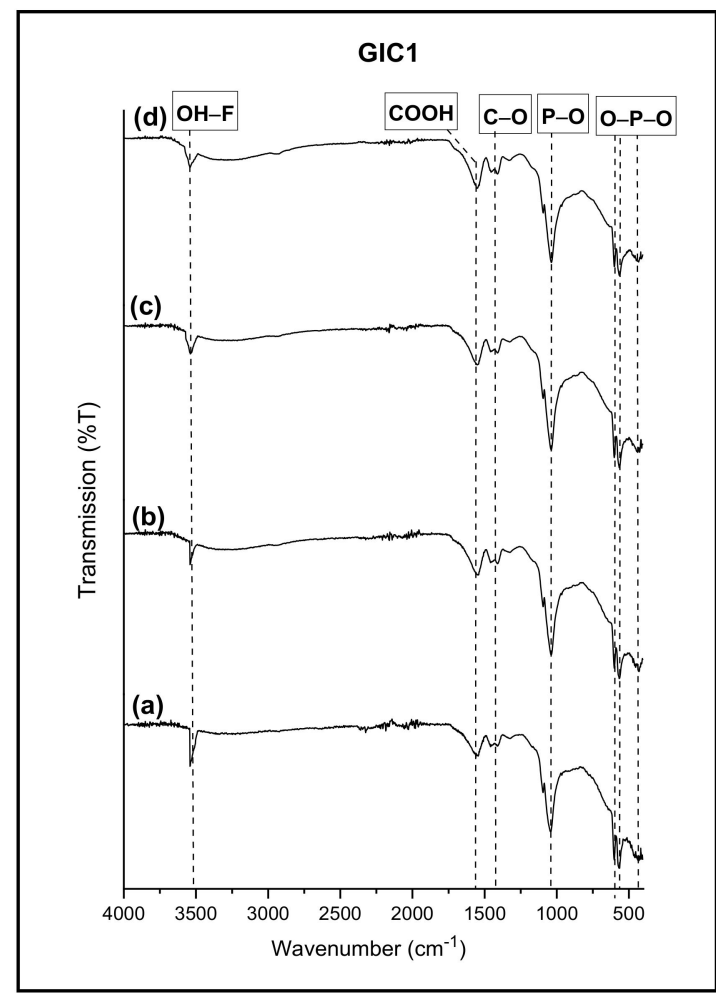

(B)

Figure 4. FTIR pattern of GIC (A) and GIC1 (B) sample for (a) 1 day, (b) 7 days, (c) 14 days, and (d) 21 days of ageing time. 
Table 3. Vibrational modes assigned for GIC and GIC1 samples.

\begin{tabular}{ccc}
\hline Wavenumber $\left(\mathbf{c m}^{-\mathbf{1}}\right)$ & Vibrational Mode & References \\
\hline$\sim 440$ & $\mathrm{v}_{2}$ O-P-O bending & {$[19,20]$} \\
$\sim 570, \sim 600$ & $\mathrm{v}_{4}$ O-P-O bending & {$[4,21-24]$} \\
$\sim 1020$ & $\mathrm{v}_{3}$ asymmetric P-O stretching & {$[19,20]$} \\
$\sim 1460$ & C-O vibration & {$[21]$} \\
$\sim 1550$ & Asymmetric COOH & {$[25]$} \\
$\sim 3400$ & OH vibration & {$[26,27]$} \\
$\sim 3550$ & OH-F vibration & {$[26,27]$} \\
\hline
\end{tabular}

\subsection{Field Emission Scanning Electron Microscopy (FESEM) Analysis}

Microstructures of GIC and GIC1 samples at different ageing times are shown in Figure 5. The observation of irregular shape of glass ceramics structure with non-uniform particle distribution was detected in both cement samples, as seen in FESEM images. The formation of needle-like and spherical particles was observed on the surface of glass ceramics particles. Besides, no significant difference was detected in the samples when compared to samples with different ageing time.

\subsection{Energy Dispersive X-ray (EDX) Analysis}

Table 4 shows the chemical composition of the GIC and GIC1 samples at 1 day of ageing time. The chemical elements existed were oxygen $(\mathrm{O})$, carbon $(\mathrm{C})$, calcium $(\mathrm{Ca})$, aluminum $(\mathrm{Al})$, phosphorus $(\mathrm{P})$, silicon $(\mathrm{Si})$, fluorine $(\mathrm{F})$ and sodium $(\mathrm{Na})$. The most element detected in GIC and GIC1 samples was $\mathrm{O}$ with the respective 42.54 and $45.20 \%$. Meanwhile, C existed with 22.86 and $20.90 \%$, while Al element was found in the GIC and GIC1 sample with 7.18 and $7.11 \%$, respectively. The detection of $P$ with 5.11 and $5.16 \%$ as well as Si element with 4.33 and $3.67 \%$ in the respective GIC and GIC1 were recorded from EDX analysis. Element $\mathrm{F}$ existed as a minor element with 3.87 and $3.91 \%$ while $\mathrm{Na}$ consisted at about 1.30 and $1.15 \%$ in the respective GIC and GIC1 samples.

Table 4. Chemical composition of GIC and GIC1 samples at 1 day of ageing time.

\begin{tabular}{ccc}
\hline \multirow{2}{*}{ Element } & \multicolumn{2}{c}{ Weight Percentage (\%) } \\
\cline { 2 - 3 } & GIC & GIC1 \\
\hline $\mathrm{O}$ & 42.54 & 45.20 \\
$\mathrm{C}$ & 22.86 & 20.90 \\
$\mathrm{Ca}$ & 12.81 & 12.90 \\
$\mathrm{Al}$ & 7.18 & 7.11 \\
$\mathrm{P}$ & 5.11 & 5.16 \\
$\mathrm{Si}$ & 4.33 & 3.67 \\
$\mathrm{~F}$ & 3.87 & 3.91 \\
$\mathrm{Na}$ & 1.30 & 1.15 \\
\hline Total & 100.00 & 100.00 \\
\hline
\end{tabular}




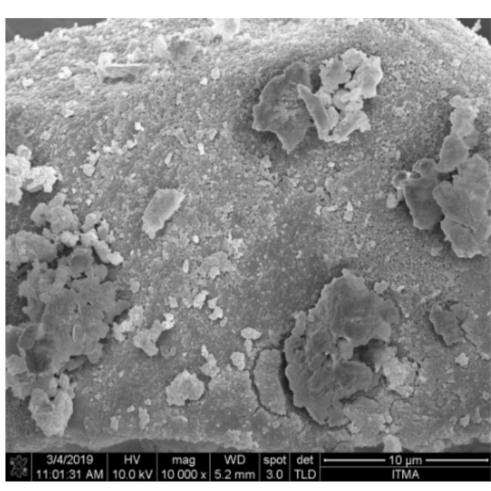

(a)

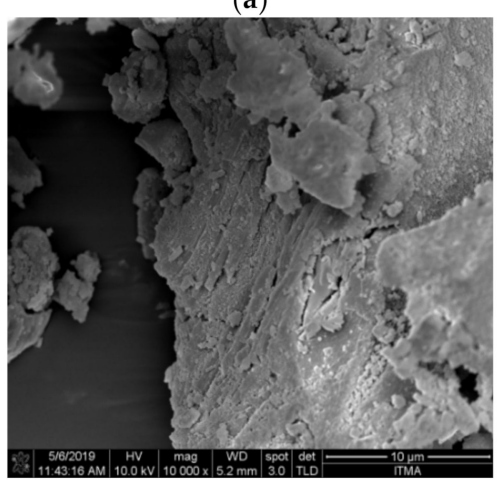

(c)

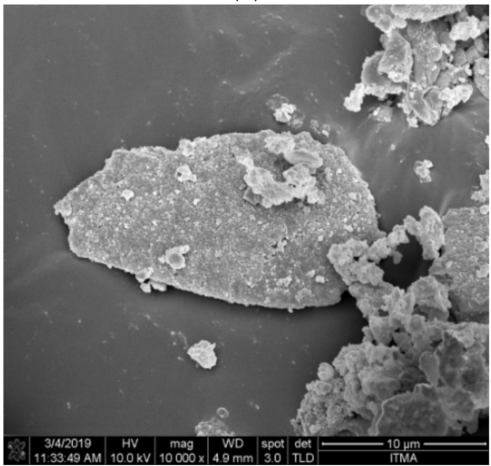

(e)

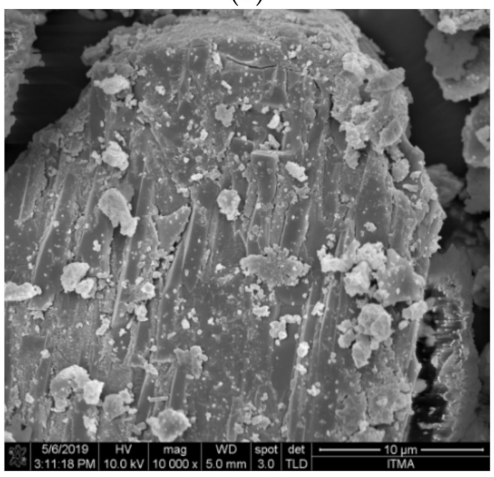

(g)

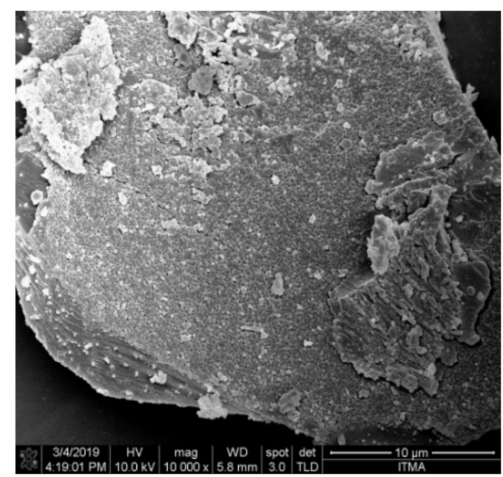

(b)

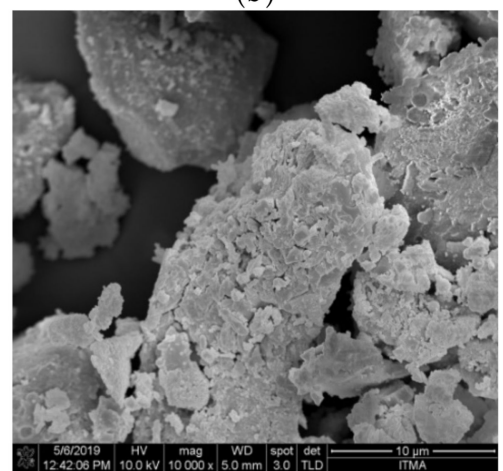

(d)

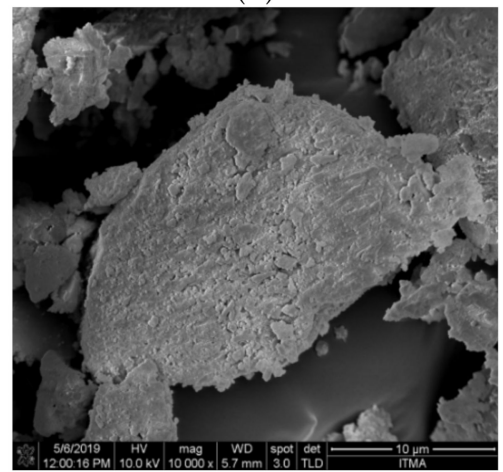

(f)

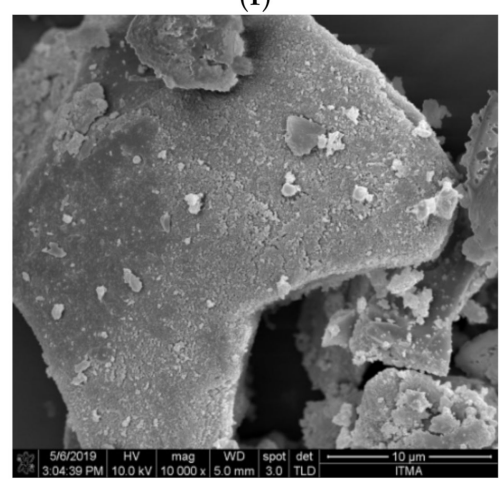

(h)

Figure 5. FESEM micrograph under magnification of 10,000 $\times$ for samples (a) GIC 1 day, (b) GIC 7 days, (c) GIC 14 days, (d) GIC 21 days, (e) GIC1 1 day, (f) GIC1 7 days, (g) GIC1 14 days, and (h) GIC1 21 days.

\section{Discussion}

In this work, density measurement was used to observe the physical properties of both GIC and HA-added GIC samples at different ageing time. The density results in 
Figure 1 and Table 1 revealed an increment in density of GIC with the addition of HA powder. This is due to high density of HA compared to ASF glass ceramics samples. In this case, the measured density of ASF glass ceramics was $2.561 \mathrm{~g} / \mathrm{cm}^{3}$ while the density of HA used in this work was $2.673 \mathrm{~g} / \mathrm{cm}^{3}$. According to a study, the increase in the density of HA-added GIC samples agrees qualitatively with the one, as predicted by the composition relation, and might be due to the replacement of high density of HA powders [20]. Thus, the density of HA which has a higher density was proposed to dominate the density of cement samples. Besides, the density of GIC and GIC1 samples was observed to increase as the ageing time increased from 1 day to 21 days. The increase in density along with ageing time is due to the increment in ratio of bound to unbound water $[25,28]$. The reaction in the GIC matrix occurs with the presence of water as a medium of setting reaction over a period of time. Moreover, water acts as a medium of reaction which helps in maturation and hardening process of cement.

The results of compressive strength test presented in Figure 2 and Table 2 found that the addition of HA into GIC resulted in higher compressive strength compared to GIC without HA addition. This is due to the presence of crystal phase in the glass structure of glass ionomer $[23,29]$. Metal ions such as $\mathrm{Ca}^{2+}$ are displaced from the added HA, therefore increased the participation of ions in acid base reaction. The setting reaction that occurs when there is addition of HA into GIC has been explained in few studies [21,30]. Upon addition of $\mathrm{HA}$ into $\mathrm{GIC}, \mathrm{H}^{+}$from acid polymer attacks the ceramic particles in the polysalt bridge formation and cross-linking, thus forming an intermediate layer from the interaction. The intermediate layer is very resistant to acid and is difficult to break. Therefore, the addition of HA into GIC enhance the mechanical strength of the resulting GIC $[23,30,31]$. Figure 6 explained the schematic diagram of setting reaction of HA added GIC.

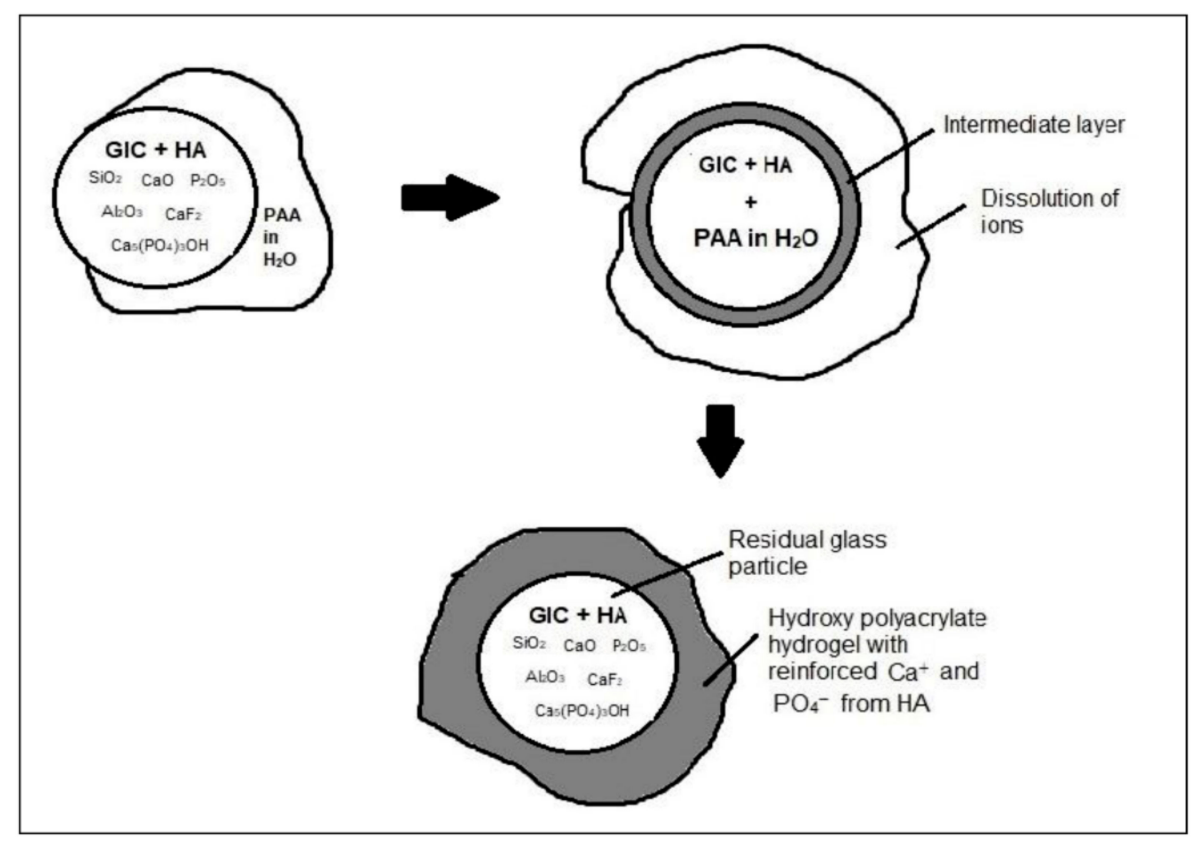

Figure 6. Schematic diagram of setting reaction of HA-added GIC.

Besides, the compressive strength of both GIC and GIC1 samples increased as ageing time increased. The immersion of cements into deionized water as a medium of reaction at different periods of time allows reaction between the GIC matrix to occur. Longer ageing time seemed to improve the strength of the GIC. Compressive strength results of the cement samples are related to the density of the samples. The density of GIC samples affects the mechanical properties of the set cement [4]. The addition of HA resulted in higher density compared to GIC without the HA addition. Such results are in line with the observations of Goenka et al. [4] who reported that the samples of the HA-added GIC resulted in increased 
hardness due to increased density of the set cement. Besides, some studies reported that the addition of certain volume of HA and the role of PAA in cement caused an increase in crosslink density of the cement structure, thus helping to increase the mechanical strength of the GIC $[4,28]$.

Through Turkey-Kramer post-hoc evaluation, the significant difference in density and compressive strength of each cement samples when compared between different ageing times was determined and the results were presented in Tables 1 and 2, respectively. According to density results in Table 1, the comparison between different ageing time revealed that not all GIC and GIC1 samples showed significantly different results. Meanwhile, the compressive strength results shown in Table 2 revealed the significantly different results when compared to different ageing time and this situation occurred in both GIC and GIC1 samples. The increase in ageing time caused the significant increase in compressive strength value. Several studies reported that no significant difference was observed in compressive strength between GIC without HA addition and HA-added GIC samples at different ageing time [32,33]. Thereby, it can be concluded that HA addition into GIC composition did not give any significant effect in compressive strength of the resulting GIC.

XRD patterns in Figure 3 revealed the formation of FA crystal phase in GIC samples at 1,7, 14 and 21 days of ageing time. This is due to the utilization of ASF glass ceramics as base powder in the formulation of GIC. The study of ASF glass ceramics had been done by some researchers and found that the ASF glass ceramics with similar composition caused the development of FA crystal phase [10-12]. The addition of a small weight percentage of HA did not affect the XRD pattern except for the detection of FHA phase. According to some studies, the formation of FHA in modified GIC samples of different ageing time is due to the substitution of hydroxyl ion $\left(\mathrm{OH}^{-}\right)$by fluoride ion $\left(\mathrm{F}^{-}\right)$that occurred in the apatite composition $[28,34]$. The reaction of the released fluoride ion with the HA crystal was summarized in general by Equation (3) [35]. In this case, the substitution of $\mathrm{F}^{-}$ion into the apatite crystal caused the formation of the FHA crystal phase. FHA crystal was found to occur naturally in human bone and teeth. Owing better mechanical and chemical properties, FA and FHA have been attracting a great attention in biomedical application especially for dental restoration [36].

$$
\mathrm{Ca}_{10}\left(\mathrm{PO}_{4}\right)_{6}(\mathrm{OH})_{2}+\mathrm{F}^{-} \rightarrow \mathrm{Ca}_{10}\left(\mathrm{PO}_{4}\right)_{6} \mathrm{FOH}+\mathrm{OH}^{-}
$$

FTIR patterns of GIC and GIC1 samples at different ageing times depicted in Figure 4 revealed the existence of similar spectral bands. The appearance of the spectral band at $\sim 400 \mathrm{~cm}^{-1}$ was belonged to double degenerate $\mathrm{O}-\mathrm{P}-\mathrm{O}$ bending mode $\left(\mathrm{v}_{2}\right)$ indicated by phosphate group in apatite sample $[19,20]$. Next, the emergence of triple degenerate $\mathrm{O}-\mathrm{P}-\mathrm{O}$ bending mode $\left(\mathrm{v}_{4}\right)$ which appeared at both intense peaks at wavenumber $\sim 570$ and $\sim 600 \mathrm{~cm}^{-1}$. Another occurrence of phosphate chemical bonding was observed at an intense peak of $\sim 1020 \mathrm{~cm}^{-1}$ which represented asymmetric $\mathrm{P}-\mathrm{O}$ stretching mode $\left(\mathrm{v}_{3}\right)$. According to related literature, more than one distinction site of $\mathrm{PO}_{4}{ }^{3-}$ vibration modes was found in the FTIR spectral wavenumber of cement sample which proved the formation of apatite phase inside the cement samples [4,21-24].

On the other hand, the carbonate group depicted by $\mathrm{C}-\mathrm{O}$ vibration mode at wavenumber $\sim 1460 \mathrm{~cm}^{-1}$ confirmed the involvement of carbonate precursors in the production of GIC samples. Besides, Khiri and co-workers explained the formation of asymmetric $\mathrm{COOH}$ band at $1550 \mathrm{~cm}^{-1}$ which originated from the carboxyl group in PAA used in the formulation of GIC [25]. The cross-linking reaction of the carboxylic group was observed in all cement samples due to an active reaction that occurred between PAA and ASF glass ceramics. Next, a broad absorption band was discovered at high frequency of wavenumber $\sim 3400 \mathrm{~cm}^{-1}$ which indicated the occurrence of $\mathrm{OH}$ vibration mode. Jekonovic et al. [26] and Montazeri et al. [27] stated that the occurrence of the vibrational mode is due to stretching of intermolecular $\mathrm{H}$ bonds caused by water absorption. At the same time, the existence of this spectral band showed the presence of water during cement preparation [26]. 
The only difference spotted in FTIR spectral of GIC1 sample compared to GIC sample was the existence of hydroxyl group by incorporation of fluorine ion which was represented by OH-F vibration mode at wavenumber $\sim 3550 \mathrm{~cm}^{-1}$, claimed the formation of FHA phase in GIC1 sample. Studies from Eslamia et al. [37] and Jokanović et al. [27] explained that the band existed at $3550 \mathrm{~cm}^{-1}$ in HA samples due to stretching mode of hydrogen bonded $\mathrm{OH}^{-}$ ion. When hydroxyl groups are partially replaced with fluoride ions in HA, the stretching mode of $\mathrm{OH}^{-}$can shift to the new band that arises from OH-F bond. In FHA, OH band appeared at around $3550 \mathrm{~cm}^{-1}$ indicating that the $\mathrm{OH}-\mathrm{F}$ interaction influences all the $\mathrm{OH}^{-}$ ions present in the samples.

FESEM morphology of both GIC and GIC1 samples in Figure 5 showed the irregular shape of glass ceramics structure with non-uniform particle distribution. The detection of apatite crystals by the formation of needle-like and spherical particles were observed to disperse on the surface of the glass ceramics particle. This observation is in conjunction with the findings found by Khaghani and co-workers, who investigated the SEM structure of HA incorporation into GIC composition [29]. According to some literatures, hexagonal structure of apatite was illustrated by rod or needle-like and spherical structure $[26,27,38]$. Due to high adsorbability, apatite crystals with rod-like morphology have shown favorable biocompatibility and bioactivity, as the corresponding interactions of Van der Waals are proportional to the large rod surface region [39,40].

EDX analysis was utilized to investigate the chemical composition of cement samples at 1 day of ageing time and the results were presented in Table 4. Most of the elements detected by EDX test originated from chemical compounds used in the preparation of glass ceramics powder which then used as base powder for GIC formulation, meanwhile C was developed from polyacid used in initiating the reaction of GIC. Oxygen existed as the major element consisted in the cement samples due to consumption of oxide elements in the fabrication of ASF glass ceramics powder. A study from Rahman et al. [12] explained the existence of minor elements such as $\mathrm{Na}, \mathrm{Si}, \mathrm{Al}$, and other elements make up a majority of SLS glasses, which then utilized in the making of base powder of the cement. In tooth structure, the hardest and highly mineralized substance, called enamel consists of $96 \%$ inorganic matter, $1-2 \%$ organic matter and $2-3 \%$ water. The majority of inorganic matter which make up the enamel structure is owned by distinct crystalline phases of HA. Calcium (Ca) and phosphorus (P) are essential elements composed in HA, and the composition of both elements is crucial for the saturation of apatite that improves the process of remineralization [10].

\section{Conclusions}

In the current study, CS and SLS glass had been exploited to fabricate ASF glass ceramics which subsequently used in the formulation of GIC. The physical, mechanical and structural properties of GIC formulated based on ASF glass ceramics as base silicate powder was enhanced by the addition of HA powder, which revealed the enhancement in density and compressive strength test along with the formation of FHA crystal phase from structural studies. Besides, ageing time also had been observed to improve the properties of the resulting GIC. In a nutshell, the improved properties of physical, structural and mechanical encourage the use of HA-added GIC in biomedical application especially for dental restoration.

Author Contributions: W.N.W.J., K.A.M. and M.H.M.Z. take part in planning and conducting the design of the study, as well as preparing the manuscript; N.Z., M.Z.A.K. and R.A.J. participated in experimental procedure, as well as analysis part. N.A.A.R. and E.K. assisted as project conceptualization and analysed the data of ASF glass ceramics used in the GIC formulation. All authors have read and agreed to the published version of the manuscript.

Funding: This research was funded by Malaysian Ministry of Higher Education (MOHE) under Fundamental Research Grant Scheme (FRGS) grant number 5540163 and also Universiti Putra Malaysia under Inisiatif Putra Siswazah (IPS) grant number 9627400. 
Conflicts of Interest: The authors declare no conflict of interest.

\section{References}

1. Wilson, A.D.; Kent, B.E. A new translucent cement for dentistry, the glass ionomer cement. J. Chem. Technol. Biotechnol. 1971, 21,313. [CrossRef]

2. $\quad$ McLean, J.W.; Gasser, O. Glass-cermet cements. Quintessence Int. 1985, 16, 333-343.

3. Moshaverinia, A.; Roohpour, N.; Chee, W.W.; Schricker, S.R. A review of powder modifications in conventional glass-ionomer dental cements. J. Mater. Chem. 2011, 21, 1319-1328. [CrossRef]

4. Goenka, S.; Balu, R.; Kumar, T.S. Effects of nanocrystalline calcium deficient hydroxyapatite incorporation in glass ionomer cements. J. Mech. Behav. Biomed. Mater. 2012, 7, 69-76. [CrossRef] [PubMed]

5. Shiekh, R.A.; Rahman, A.I.; Luddin, N. Modification of glass ionomer cement by incorporating hydroxyapatite-silica nano-powder composite: Sol-gel synthesis and characterization. Ceram. Int. 2014, 40, 3165-3170. [CrossRef]

6. Sharafeddin, F.; Feizi, N. Evaluation of the effect of adding micro-hydroxyapatite and nano-hydroxyapatite on the microleakage of conventional and resin-modified Glass-ionomer Cl V restorations. J. Clin. Exp. Dent. 2017, 9, e242-e248. [CrossRef]

7. Noori, A.J.; Kareem, F.A. Setting time, mechanical and adhesive properties of magnesium oxide nanoparticles modified glassionomer cement. J. Mater. Res. 2019, 9, 1809-1818. [CrossRef]

8. Rahman, I.A.; Ghazali, N.A.M.; Bakar, W.Z.W.; Masudi, S.A.M. Modification of glass ionomer cement by incorporating nanozirconia-hydroxyapatite-silica nano-powder composite by the one-pot technique for hardness and aesthetics improvement. Ceram. Int. 2017, 43, 13247-13253. [CrossRef]

9. Ramsden, R.T.; Herdman, R.C.T.; Lye, R.H. Ionomeric bone cement in otoneurological surgery. J. Laryngol. Otol. 1992, 106, 949-953. [CrossRef]

10. Abdul Jalil, R.; Amin Matori, K.; Mohd Zaid, M.H.; Zainuddin, N.; Ahmad Khiri, M.Z.; Abdul Rahman, N.A.; Wan Jusoh, W.N.; Kul, E. A study of fluoride-containing bioglass system for dental materials derived from clam shell and soda lime silica glass. J. Spectrosc. 2020, 2020, 1-9. [CrossRef]

11. Jusoh, W.N.W.; Matori, K.A.; Zaid, M.H.M.; Zainuddin, N.; Khiri, M.Z.A.; Rahman, N.A.A.; Jalil, R.A.; Kul, E. Effect of sintering temperature on physical and structural properties of Alumino-Silicate-Fluoride glass ceramics fabricated from clam shell and soda lime silicate glass. Results Phys. 2019, 12, 1909-1914. [CrossRef]

12. Rahman, N.A.A.; Matori, K.A.; Zaid, M.H.M.; Zainuddin, N.; Ab Aziz, S.; Khiri, M.Z.A.; Jalil, R.A.; Jusoh, W.N.W. Fabrication of Alumino-Silicate-Fluoride based bioglass derived from waste clam shell and soda lime silica glasses. Results Phys. 2019, 12, 743-747. [CrossRef]

13. Fernandes, H.R.; Gaddam, A.; Rebelo, A.; Brazete, D.; Stan, G.E.; Ferreira, J.M. Bioactive glasses and glass-ceramics for healthcare applications in bone regeneration and tissue engineering. Materials 2018, 11, 2530. [CrossRef]

14. Henao, J.; Poblano-Salas, C.; Monsalve, M.; Corona-Castuera, J.; Barceinas-Sanchez, O. Bio-active glass coatings manufactured by thermal spray: A status report. J. Mater. Res. Technol. 2019, 8, 4965-4984. [CrossRef]

15. Bauccio, M. ASM Engineered Materials Reference Book; CRC Press LLC: Boca Raton, FL, USA, 1994.

16. Pfaender, H.G. Schott Guide to Glass; Springer Science \& Business Media: Berlin, Germany, 2012.

17. Awang-Hazmi, A.J.; Zuki, A.B.Z.; Noordin, M.M.; Jalila, A.; Norimah, Y. Mineral composition of the cockle (Anadara granosa) shells of west coast of Peninsular Malaysia and it's potential as biomaterial for use in bone repair. J. Anim. Vet. Adv. 2007, $6,591-594$

18. Loyd, D. Physics Lab Manual; Cengage Learning: Orlando, FL, USA, 2007.

19. Mandal, T.; Mishra, B.K.; Garg, A.; Chaira, D. Optimization of milling parameters for the mechanosynthesis of nanocrystalline hydroxyapatite. Powder Technol. 2014, 253, 650-656. [CrossRef]

20. Zarifah, N.A.; Matori, K.A.; Sidek, H.A.A.; Wahab, Z.A.; Salleh, M.M.; Zainuddin, N.; Khiri, M.Z.A.; Farhana, N.S.; Omar, N.A.S. Effect of hydroxyapatite reinforced with $45 S 5$ glass on physical, structural and mechanical properties. Procedia Chem. 2016, 19, 30-37. [CrossRef]

21. Moshaverinia, A.; Ansari, S.; Moshaverinia, M.; Roohpour, N.; Darr, J.A.; Rehman, I. Effects of incorporation of hydroxyapatite and fluoroapatite nanobioceramics into conventional glass ionomer cements (GIC). Acta Biomater. 2008, 4, 432-440. [CrossRef] [PubMed]

22. Garcia-Contreras, R.; Scougall-Vilchis, R.J.; Contreras-Bulnes, R.; Sakagami, H.; Morales-Luckie, R.A.; Nakajima, H. Mechanical, antibacterial and bond strength properties of nano-titanium-enriched glass ionomer cement. J. Appl. Oral Sci. 2015, 23, 321-328. [CrossRef] [PubMed]

23. Barandehfard, F.; Rad, M.K.; Hosseinnia, A.; Khoshroo, K.; Tahriri, M.; Jazayeri, H.E.; Moharamzadeh, K.; Tayebicgh, L. The addition of synthesized hydroxyapatite and fluorapatite nanoparticles to a glass-ionomer cement for dental restoration and its effects on mechanical properties. Ceram. Int. 2016, 42, 17866-17875. [CrossRef]

24. Alatawi, R.A.; Elsayed, N.H.; Mohamed, W.S. Influence of hydroxyapatite nanoparticles on the properties of glass ionomer cement. J. Mater. Res. Technol. 2019, 8, 344-349. [CrossRef]

25. Khiri, M.Z.A.; Matori, K.A.; Zaid, M.H.M.; Abdullah, A.C.; Zainuddin, N.; Jusoh, W.N.W.; Jalil, R.A.; Rahman, N.A.A.; Kul, E.; Wahab, S.A.A.; et al. Soda lime silicate glass and clam shell act as precursor in synthesize calcium fluoroaluminosilicate glass to fabricate glass ionomer cement with different ageing time. J. Mater. Res. Technol. 2020, 9, 6125-6134. [CrossRef] 
26. Montazeri, N.; Jahandideh, R.; Biazar, E. Synthesis of fluorapatite-hydroxyapatite nanoparticles and toxicity investigations. Int. J. Nanomed. 2011, 6, 197-201.

27. Jokanović, V.; Čolović, B.; Jović, N.; Babić-Stojić, B.; Jokanović, B. Mechanochemical and low-temperature synthesis of nanocrystalline fluorohydroxyapatite/fluorapatite. Int. J. Appl. Ceram. Technol. 2013, 10, 957-969. [CrossRef]

28. Nicholson, J.W. Chemistry of glass-ionomer cements: A review. Biomaterials 1998, 19, 485-494. [CrossRef]

29. Khaghani, M.; Alizadeh, S.; Doostmohammadi, A. Influence of incorporating fluoroapatite nanobioceramic on the compressive strength and bioactivity of glass ionomer cement. J. Dent. Biomater. 2016, 3, 276-283.

30. Arita, K.; Yamamoto, A.; Shinonaga, Y.; Harada, K.; Abe, Y.; Nakagawa, K.; Sugiyama, S. Hydroxyapatite particle characteristics influence the enhancement of the mechanical and chemical properties of conventional restorative glass ionomer cement. Dent. Mater. J. 2011, 30, 672-683. [CrossRef] [PubMed]

31. Bali, P.; Prabhakar, A.R.; Basappa, N. An invitro comparative evaluation of compressive strength and antibacterial activity of conventional GIC and hydroxyapatite reinforced GIC in different storage media. J. Clin. Diagn. Res. 2015, 9, ZC51-ZC55. [CrossRef]

32. Yap, A.U.J.; Pek, Y.S.; Kumar, R.A.; Cheang, P.; Khor, K.A. Experimental studies on a new bioactive material: HAIonomer cements. Biomaterials 2002, 23, 955-962. [CrossRef]

33. Shinonaga, Y.; Arita, K.; Nishimura, T.; Chiu, S.Y.; Chiu, H.H.; Abe, Y.; Sonomoto, M.; Harada, K.; Nagaoka, N. Effects of porous-hydroxyapatite incorporated into glass-ionomer sealants. Dent. Mater. J. 2015, 34, 196-202. [CrossRef]

34. Wei, M.; Evans, J.H.; Bostrom, T.; Grøndahl, L. Synthesis and characterization of hydroxyapatite, fluoride-substituted hydroxyapatite and fluorapatite. J. Mater. Sci. Mater. Med. 2003, 14, 311-320. [CrossRef] [PubMed]

35. Šupová, M. Substituted hydroxyapatites for biomedical applications: A review. Ceram. Int. 2015, 41, 9203-9231. [CrossRef]

36. Pajor, K.; Pajchel, L.; Kolmas, J. Hydroxyapatite and fluorapatite in conservative dentistry and oral implantology-A review. Materials 2019, 12, 2683-2699. [CrossRef]

37. Eslamia, H.; Moztarzadeha, F.; Khoshroob, K.; Ashuria, M.; Tahriria, M. Synthesis and characterization of $\mathrm{Ca}_{5}\left(\mathrm{PO}_{4}\right)_{3}(\mathrm{OH})$ $(0 \leq x \leq 1)$ nanopowders via $\mathrm{pH}$-cycling method as bioceramics. In Proceedings of the 4th International Conference on Nanostructures (ICNS4), Kish Island, Iran, 12-14 March 2012.

38. Azami, M.; Jalilifiroozinezhad, S.; Mozafari, M. Calcium fluoride/hydroxyfluorapatite nanocrystals as novel biphasic solid solution for tooth tissue engineering and regenerative dentistry. Key Eng. Mater. 2012, 493, 626-631. [CrossRef]

39. Sasani, N.; Khadivi, A.H.; Zebarjad, S.M.; Vahdati, K.J. Characterization of rod-like high-purity fluorapatite nanopowders obtained by sol-gel method. J. Ultrafine Grained Nanostruct. Mater. 2013, 46, 31-37.

40. Zandi, M.; Mirzadeh, H.; Mayer, C.; Urch, H.; Eslaminejad, M.B.; Bagheri, F.; Mivehchi, H. Biocompatibility evaluation of nano-rod hydroxyapatite/gelatin coated with nano-HAp as a novel scaffold using mesenchymal stem cells. J. Biomed. Mater. Res. A 2010, 92, 1244-1255. [CrossRef] 